\title{
Numeric simulation of the pulsation bottle for a reciprocating compressor in dynamic regime
}

\author{
Ion Pana ${ }^{1 *}$, and Florinel Dinu ${ }^{2}$ \\ ${ }^{1}$ University of Petroleum and Gas, Department of Mechanical Engineering, 39 Bucuresti Avenue, \\ Ploiesti, Romania \\ ${ }^{2}$ University of Petroleum and Gas, Department of Well Drilling, Extraction and Transport of \\ Hydrocarbons, 39 Bucuresti Avenue, Ploiesti, Romania
}

\begin{abstract}
The pulsation bottles are mounted at the inlet and outlet of / from the reciprocating compressor cylinders to even out the gas parameters (pressure and temperature). They ensure stable working conditions in the compressor cylinders and eliminate / reduce vibrations. The sizing of the pulsation bottle is done based on the geometric parameters of the compressor, the volume efficiency and working pressure. The use of a dynamic model made in the LMS Amesim program allows the study of a compressor with a set of pulsation bottles at the modification of: the pressure and temperature at the inlet / outlet of the compressor, the speed of the compressor the volume of the dead space and blocking or removing of the valves. The model includes the compressor cylinder with the corresponding dead spaces, the compressor valves, the suction and discharge pipelines and crank connecting rod mechanism. The simulation takes into account of the: gas composition, temperature and pressure in the system. The variation of the pressure in the bottles can be checked under these conditions. The values of the disturbing forces for a range of working and adjustment parameters can be obtained, values that can be used in a dynamic analysis according to API 618.
\end{abstract}

\section{Introduction}

Most of the vibration problems in gas pipelines are attributed to high pressure pulsations. The pulsations generated by the compressors are turned into agitation forces at the elbows, reductions, valves, which in turn excite the connected pipeline network. Vibrations can cause stresses beyond the limit strength of the pipe material, damage to pipeline, supports and equipment. In addition, if the pulsation frequency of the source coincides with one of the natural frequencies of the pipeline / or the equipment mounted on it, the resonance will occur and the vibrations will be increased on a large scale.

The compressor assembly contains the reciprocating compressor, pulsation dampers, gas coolers and the connected piping system. Vibration of the compressor lines can contribute to the failure of the system, which can lead to unsafe situations for the human being, the environment, increased maintenance costs, and the cost of repairs. The pulsation

\footnotetext{
*Corresponding author: ion.pana@upg-ploiesti.ro
} 
analysis of the compressor must be performed before analysing the vibrations of the pipelines. Pulse analysis guidelines are given in API 618 Method 2 and vibration analysis guidelines are given in API 618 Method 3 [1].

Although wet (oil-injected) and dry (oil-free) screw compressors are widely used in many applications, limited information on pulsation and noise problems associated with these types of compressors is available. Wet screw compressors usually do not dampen noise because oil separators are used. Oil separators are mainly designed to remove oil from the gas, but the separators can attenuate the pulsation generated by the compressor. Dry screw compressors are generally supplied with suction and discharge dampers that are designed to attenuate the pulsation generated by the compressors. Most silencers are of the reactive type $[2,3]$ (Helmholtz filters), of the absorbent type or a combination of these two.

\section{Literature Overview}

For installations where reciprocating piston compressors are used, a detailed dynamic design is usually required to ensure a successful functioning. The American Petroleum Institute (API) Pulse Control Section 618 is the most commonly used for these types of studies, $[4,5]$. Atkins in [6], presents some of the best engineering practices for pulsation and vibration control for the dynamic reciprocating equipment used in the natural gas industry. Ghanbariannaeeni analyzed the vibration problems in plants with reciprocating machinery and described some procedures for calculating the pressure pulsation as well as detailed information to help the understanding of the causes of acoustically induced pulsation shaking forces [7]. It was mentioned that acoustical and mechanical study shall indicate the necessary improvements to achieve the target values of pulsation and vibration for safety and reliability.

Sometimes [8] in order to obtain an efficient pulsation reduction system, it is necessary to use two series of anti-pulsation bottles. Although apparently this method is more expensive, compared to the side effects of the one-bottle method, the proposed solution becomes economical and safe. Shejal in the paper [9] properly analyzed the vibrations of the compressor pipes, using Pulsim and Ansys software. The accuracy of the analytical solution is validated through experimental results using Brule \& Kajer analyzer for measuring the compressor lines. Dynamic forces in the reciprocating compressors from unbalanced inertial forces, gas forces inside the cylinder, acoustic agitation forces can induce severe vibrations on the compressor, pipes, vessels, equipment and supports. Article [10] based on the finite element analysis and experimental determinations, identified the vibration modes of the compressor determined by the position of moving parts and fasteners. Jia in [3] presents the results of testing and associated analyzes to suppress pressure pulsations in the valve chamber and cylinder nozzle for a reciprocating compressor with a control method based on the Helmholtz resonator. A three-dimensional acoustic model of the gas pulsation was established using the finite element method (FEM) for the compressor and the discharge pipe system with and without resonator. The results showed that the amplitude with which the presence in the valve chamber pulses was reduced by $40.4 \%$ at the installation of the resonator.

Almasi presented a model for the study of pulsation and pressure force generated into the equipment and pipelines in $[11,12]$. In order to calculate the velocity and the pressure at every point, in time, a transient one dimensional NavierStokes model was used. The information obtained from the pulsation simulation method presented allows the design of a gas transmission network that ensures the optimal solution for reducing of the pulsations. In the paper [13] Okasha used the two-port theory to model a pipeline network, where the network can be divided into several cascaded elements, each described by a transfer matrix. A pilot plane equipped with a reciprocating compressor, pipes, bends, and a vessel were 
constructed. Two cases are investigated; one with a long pipe, the other with a pulsation suppression device designed according to the API-618 standard. The comparison shows good agreement between the measured dynamic pressures and the predicted ones using 1D propagation models. The pressure variation can be effectively attenuated over the entire pipe network at different compressor speeds, when a perforated cross-flow tube is installed downstream of the anti-pulsation bottle. The pulsation damping performance is better for a longer tube with a lower perforation rate, while the hole diameter has little influence on the pulsation attenuation of the piping system [14]. Maximum recommended pressure drop values in the pulsation dampeners and suppression devices is $1 \%$ of the pressure [12]. Liu analyzed the influence of a conical cylinder discharge nozzle on pressure pulsations in a piping system with high-speed reciprocating compressor $[14,15]$. Pressure fluctuations can be effectively attenuated in the pipeline system at variable compressor speeds and pressures. There are many more forces associated with an alternate separable compressor, other than pulsations, which can lead to unacceptable vibrations. Fifer in the paper [16] discusses the main sources of forces and presents a mechanical guide that will help avoid mechanical resonance due to these sources. He emphasizes that when conducting acoustic studies, companies required in addition and mechanical analysis. There is currently no specific mechanical guidance in API Standard 618. It focuses only on the effects of pulsations.

Similar issues appear at screw compressors [17-19]. The screw compressor produces an approximately constant flow compared to reciprocating compressors. However, the risks of high frequency vibrations due to the compression process remain and can be particularly difficult to resolve. Bratek presents in [20] a case study involving three oil screw compressors in propane service. The data demonstrated how the compressor volume index and the position of the slide valve influence the pulsation and resonances. Optimized solutions to reduce pulsation and vibration are presented, including field data of the initial and modified systems.

\section{Sizing of the anti-pulsating bottles}

The anti-pulsating bottles are mounted at the inlet and outlet of / from the compressor cylinders to even out the gas parameters. This ensures stable working conditions in the compressor cylinders and eliminates / reduces vibrations. For the calculation of the presizing of the anti-pulsating bottles it is necessary to know [21-23] the compressor displacement $P_{d 1}$ (volume of gas aspirated for a double stroke):

$$
\begin{gathered}
P_{d 1}=S_{t} \cdot 1 \cdot \frac{\pi\left(2 D^{2}-d^{2}\right)}{4} \\
V_{b}=F A \cdot P_{d 1}
\end{gathered}
$$

The FA amplification factor which depends on the volumetric effciency / working pressure is determined by means of the diagrams in fig. 1.a or b; $V_{b}$ is the boottle volume. To facilitate the electronic calculation of the curves corresponding to the double action into cylinder, they was represented (fig. 1) and their equation was established, using a 2nd degree polynomial for regression. Several factors are involved in the expression of volume effciency. The ratio of the compresibility factors $f$ :

$$
f=\frac{Z_{2}}{Z_{1}}
$$


where $Z_{2}$ and $Z_{1}$ represent the compresibility factors to the exit and to the entrance on the cylinder. The expression of the compresibility factor at the entrance to the cylinder (at the exit of the cylinder will change the index 1 in 2 ) is:

$$
Z_{1}=\frac{1}{1+\frac{527393 \cdot p_{1} \cdot 10^{1,785 \cdot \delta_{g}}}{T_{1}^{3.825}}}
$$

where $p_{1}$ is the relative pressure of the gas at the inlet to the cylinder; $\delta_{g}$ relative density of the gas; $T_{1}$ absolute temperature of the gas at the inlet to the cylinder. The density of the gas $\rho_{N}$ at the entrance to the cylinder under normal conditions (at pressure $101325 \mathrm{~Pa}$ and temperature $273.15 \mathrm{~K}$ ) is:

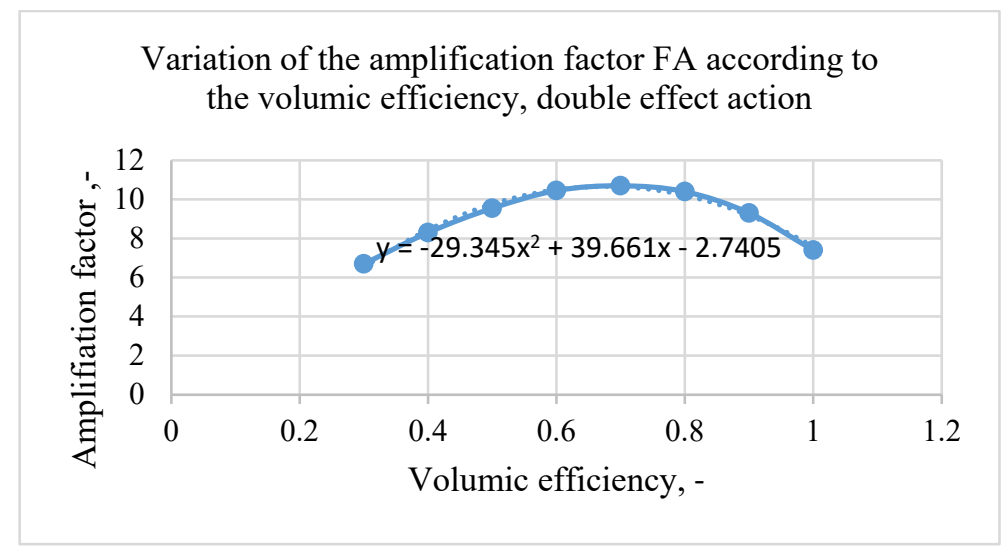

a

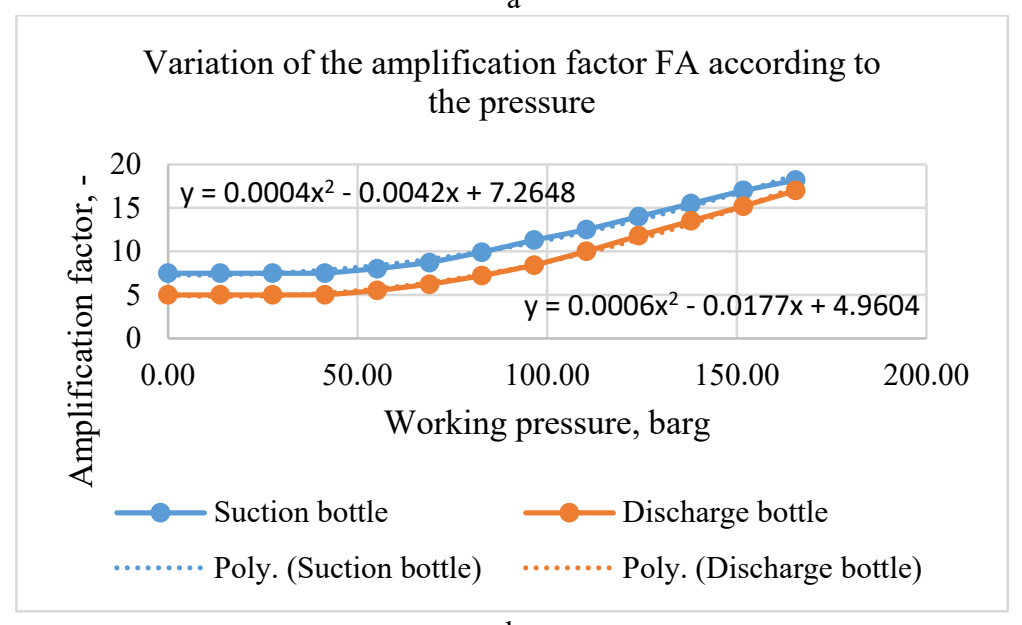

b

Fig. 1. Diagram for choosing the amplification factor when determining the volume of antipulsating cylinders: a. Function of the volumetric efficiency, Source [22]; b. Function of pressure, Source [23] (regression curve are established by the authors).

$$
\rho_{N}=\frac{M}{22.414}
$$


The molar mass of the mixture is determined by the relation:

$$
M=\sum_{i=1}^{n} y_{i} M_{i}
$$

where $y_{i}$ are the molar fractions of the components of the mixture and $M_{i}$ are their molar masses. The relative density of the gas mixture $\left(\rho_{N, \text { air }}=1,293 \frac{\mathrm{kg}}{\mathrm{m}^{3}}\right)$ is:

$$
\rho_{g}=\frac{\rho_{N}}{\rho_{N, \text { air }}}
$$

The other factors that determine the volumetric effciency are: the compression ratio $r$; $L$ the coefficient taking into account of the gas losses along the sealing segments, $L=$ $0.01-0.02,[22]$; adiabatic exponent $k ; c$ influence of dead space expressed as a ratio between the volume of dead space $V_{m}$ and the working volume of the cylinder $V_{l}$ :

$$
c=\frac{V_{m}}{V_{l}}
$$

The values of $c$ are between 0.05 and 0.2 to which the setting can be added by the dead space method. The suction volumetric efficiency is:

$$
E_{v}=0.97-\left(\frac{r^{1 / k}}{f}-1\right) c-L
$$

$r$ is the compression ratio. For the adiabatic exponent $k$ it was used the relation:

$$
k=1,9637 M^{a}+\frac{t-10}{27.7}\left(1.9927 M^{b}-1.9637 M^{a}\right)
$$

is used where $M$ is the molar mass of the mixture $\mathrm{kg} / \mathrm{kmol} ; t$ average temperature of the gas in the cylinder, ${ }^{\circ} \mathrm{C} ; \quad a, b$-dimensionless coefficients: $a=-0,1463 ; \quad b=$ -0.1543 [21]. The volumic discharge efficiency is:

$$
E_{d}=\frac{E_{v} f}{r^{1 / k}}
$$

\section{Study of the anti-pulsating bottles in the LMS Amesim program}

The recommended condition for the maximum variation of the pressure $\Delta p$ when mounting an anti-pulsating bottle is $[1,11,21,23]$, at the compressor flange (12) or at the pipeline flange (13) are respectively:

$$
\begin{gathered}
\Delta p \%=\min (3 r ; 7) \\
\Delta p \%=\frac{4.1}{p_{n}^{1 / 3}}
\end{gathered}
$$


where $p_{n}$ is the average pressure in the pipe. The API 618 standard makes recommendations regarding the level of approach to the calculation of pulses depending on the compressor power and pressure [1]. Nine zones are defined in API 618 and for the exemplified case in this paper (a compressor with a power of $107.040 \mathrm{~kW}$ and a pressure of 12 barA) is recommended the Approach 1. Acoustic filtration is not necessary to be used to eliminate / reduce pressure waves in the piping system, according to this recommendation. The exemplified system is reduced to simple bottles mounted on the inlet and outlet of compressor cylinders. In order to verify the functioning of the anti-pulsating bottles, the model in fig. 2.a was achieved (it includes 47 variables evaluated during the program execution). The scheme contains the following elements: suction network parameters temperature $(288 \mathrm{~K})$ and pressure $(4$ barA), the pressure can be changed according to an imposed law of variation; discharge network parameters temperature $(288 \mathrm{~K})$ and pressure (12 barA), the pressure can be changed according to an imposed law of variation; pulsation bottles shaped like pneumatic chambers (volume values $\mathrm{V}_{\mathrm{s}}=5061, \mathrm{~V}_{\mathrm{d}}=3591$ suction and discharge, respectively); suction pipeline (length $5 \mathrm{~m}$, inside diameter $300 \mathrm{~mm}$ ); discharge pipeline (length $100 \mathrm{~m}$, inside diameter $200 \mathrm{~mm}$ ); ; suction and discharge valves of the compressor cylinders (flow area $7854 \mathrm{~mm}^{2}$, pressure drop $0.02 \mathrm{barg} /(\mathrm{Smc} / \mathrm{s})$ ); compressor cylinders ( piston diameter $279 \mathrm{~mm}$, stroke length $418 \mathrm{~mm}$, rod /piston diameter ratio 0.25); dead space volume $12 \%$ from compressor displacement. The suction / discharge pipelines were split into six parts and a distributive wave equation submodel were used.

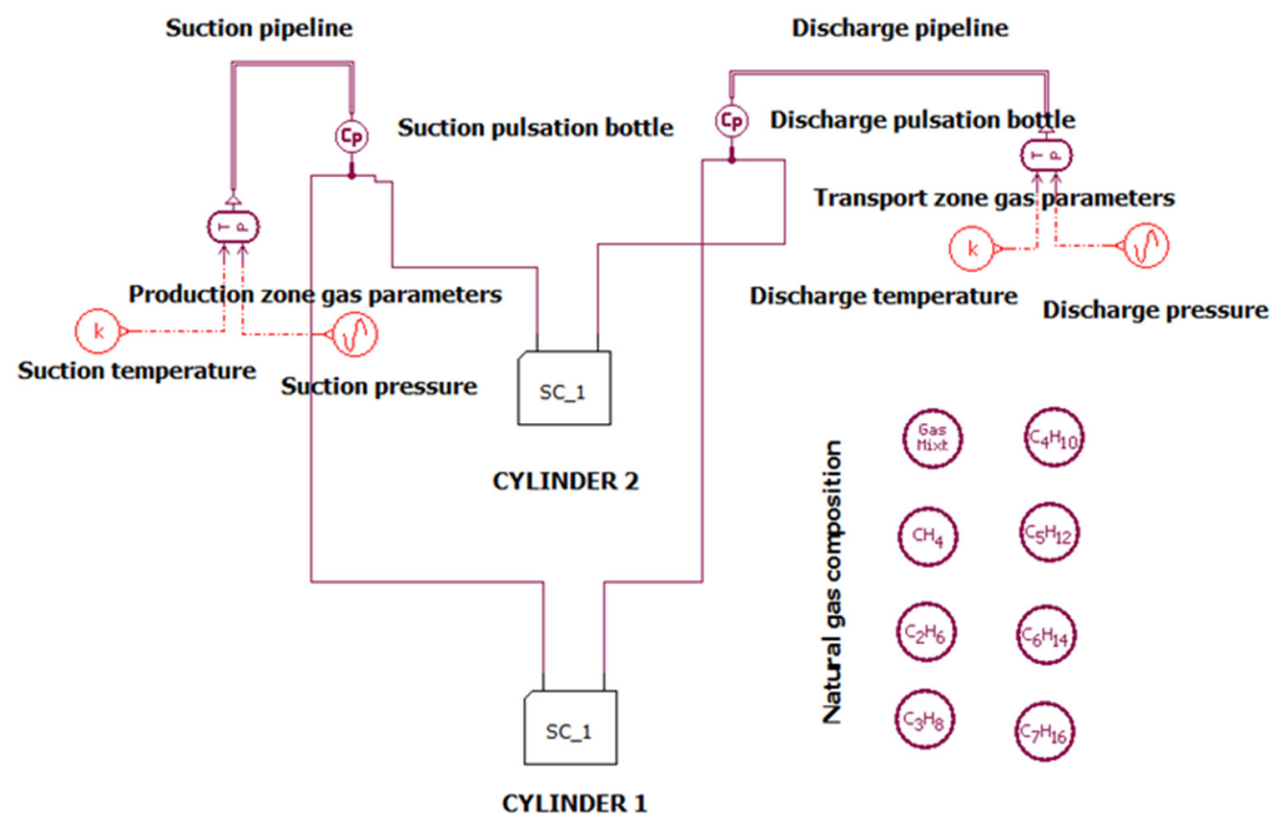




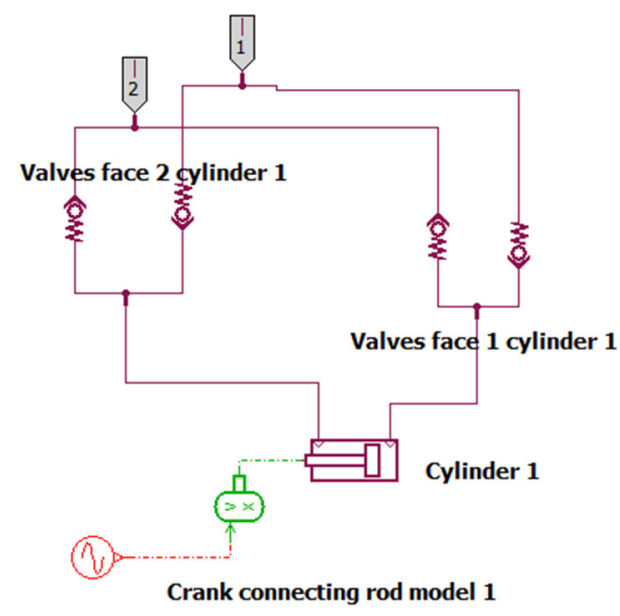

b

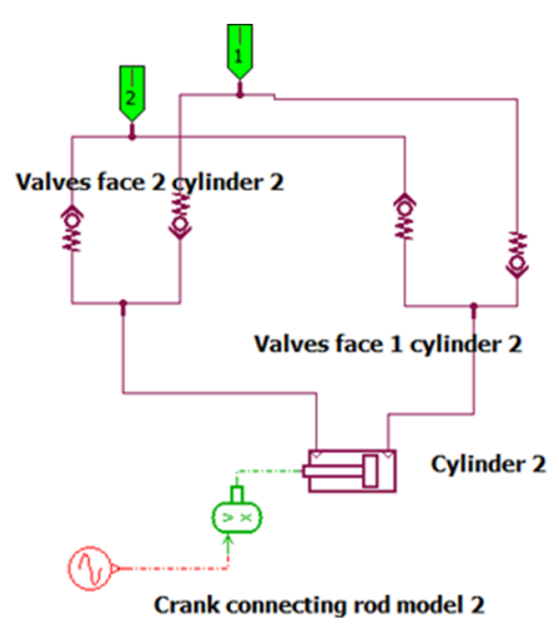

C

Fig. 2. Model of the anti-pulsation bottles in the LMS Amesim program: a. Model of the compression and pulsation bottles, cylinders 1 and 2 ; b. using of the cylinder sub model for cylinder 1 ; c. the sub model of the cylinder 2 .

The gas mixture block allows the precise introduction of the natural gas composition. The model was simplified being introduced sub models for cylinders fig. 2.b-c, in which is used the crank connecting rod model (crank radius $209 \mathrm{~mm}$ ), cranks are 90 degrees offset. For the cylinder, the geometric elements are calculated according to the volume flow $150,000 \mathrm{Scm}$ that is devised between the two cylinders fig. 3 . The phase difference between the cylinders can be observed.

\begin{tabular}{|c|c|c|}
\hline Title & Value & Unit \\
\hline (i) temperature at port 1 & \multicolumn{2}{|c|}{$293.15 \mathrm{~K}$} \\
\hline (i) pressure at port 1 & 4 & barA \\
\hline (ii) temperature at port 2 & 293.15 & $\mathrm{~K}$ \\
\hline (ii) pressure at port 2 & & barA \\
\hline gas type index & 1 & \\
\hline model & \multicolumn{2}{|l|}{ with thermal exchange } \\
\hline use initial displacement & \multicolumn{2}{|l|}{ yes } \\
\hline \#displacement of piston & \multicolumn{2}{|c|}{$0.418 \mathrm{~m}$} \\
\hline piston diameter & \multicolumn{2}{|c|}{$279 \mathrm{~mm}$} \\
\hline rod diameter & \multicolumn{2}{|c|}{$70 \mathrm{~mm}$} \\
\hline length of stroke & \multicolumn{2}{|c|}{$0.418 \mathrm{~m}$} \\
\hline dead volume at port 1 end & $a s m * 3066$ & $5 \mathrm{~cm}^{* * 3}$ \\
\hline dead volume at port 2 end & 2873 & $3 \mathrm{~cm}^{* * 3}$ \\
\hline thermal exchange coefficient & \multicolumn{2}{|c|}{$500 \mathrm{~J} / \mathrm{m}^{* *} 2 / \mathrm{K} / \mathrm{s}$} \\
\hline external temperature & \multicolumn{2}{|c|}{$293.15 \mathrm{~K}$} \\
\hline viscous friction coefficient & \multicolumn{2}{|c|}{$0 \mathrm{~N} /(\mathrm{m} / \mathrm{s})$} \\
\hline Title & Value & Unit \\
\hline $\begin{array}{l}\text { sine wave frequency } \\
\text { mean level } \\
\text { sine wave amplitude } \\
\text { phase shift }\end{array}$ & $\begin{array}{r}6 \mathrm{H} \\
0 \mathrm{n} \\
\text { omega*.209 } \mathrm{n} \\
0 \mathrm{~d}\end{array}$ & $\begin{array}{l}\mathrm{Hz} \\
\text { null } \\
\text { null } \\
\text { dearee }\end{array}$ \\
\hline
\end{tabular}

a

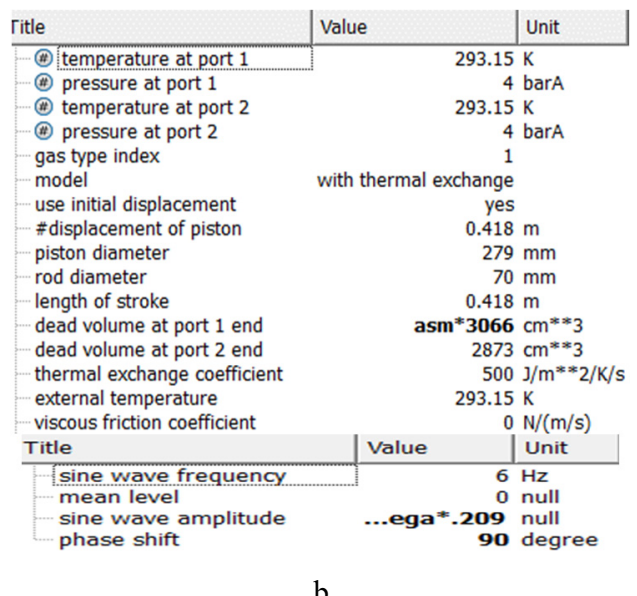

b

Fig. 3. Geometric and kinematic elements for cylinders: a. cylinder 1; b. cylinder 2. - asm dead volume ratio amplification; omega angular speed. 
[barA] - pn_actuator1 - pressure at port 1 [barA]

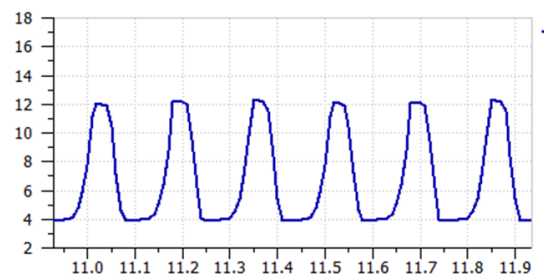

$\mathrm{X}$ : Time $[\mathrm{s}]$
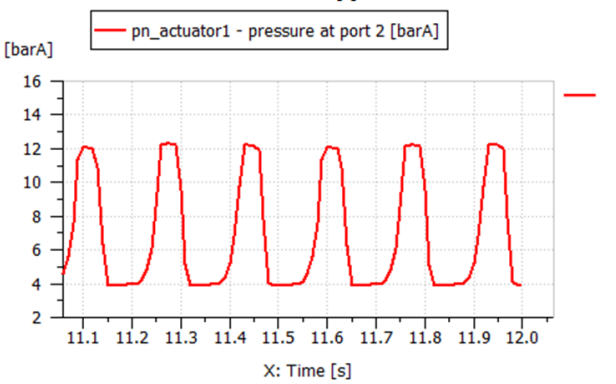

a

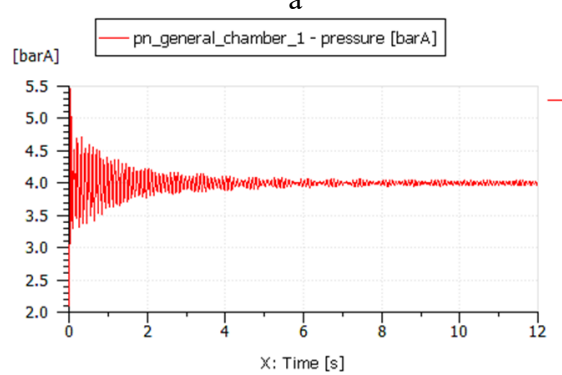

c

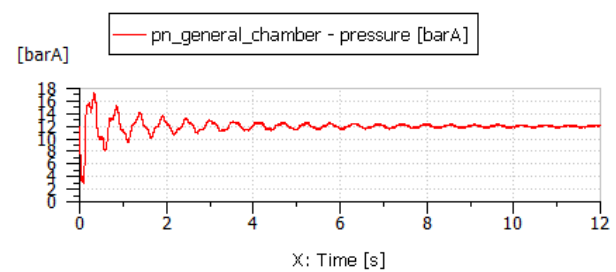

e

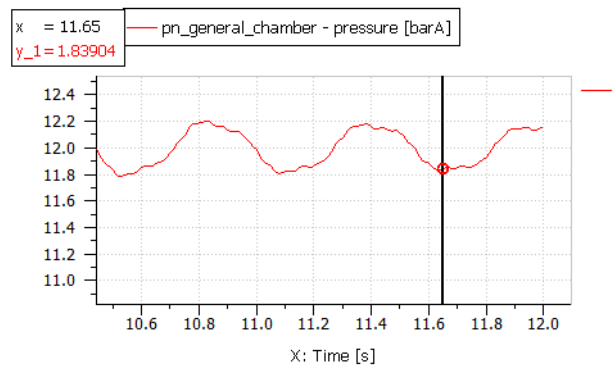

g
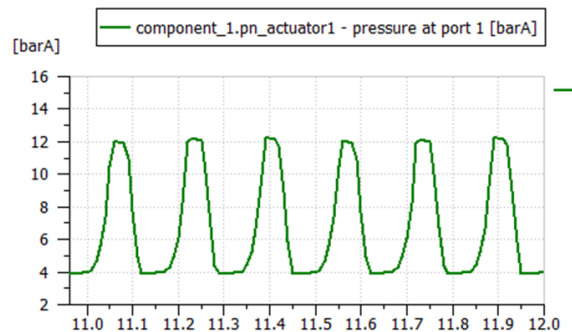

$\mathrm{X}$ : Time [s]
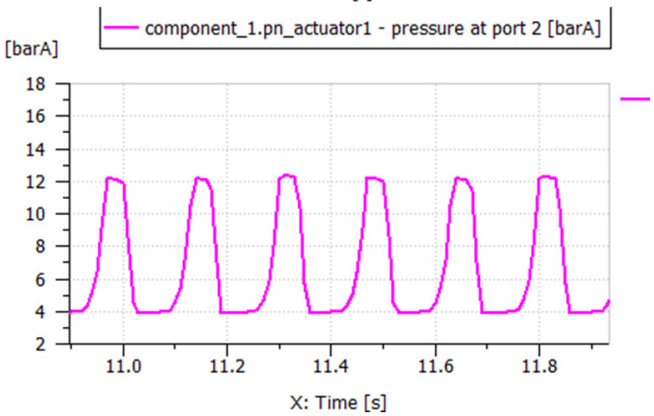

b

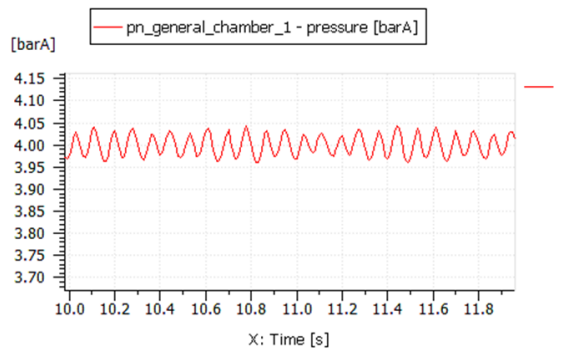

d

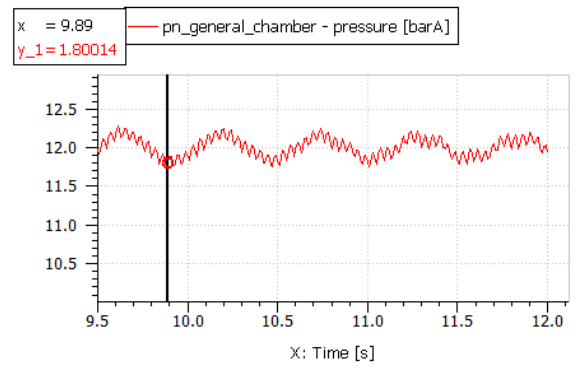

f

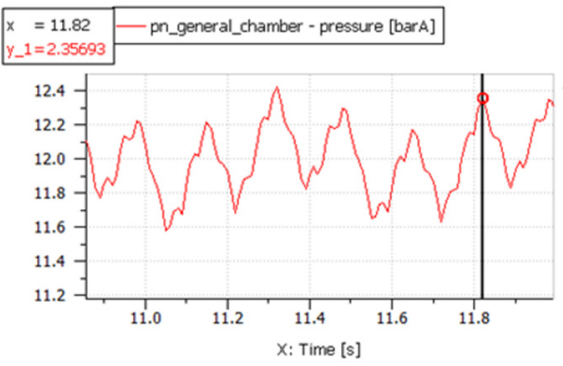

$\mathrm{h}$ 

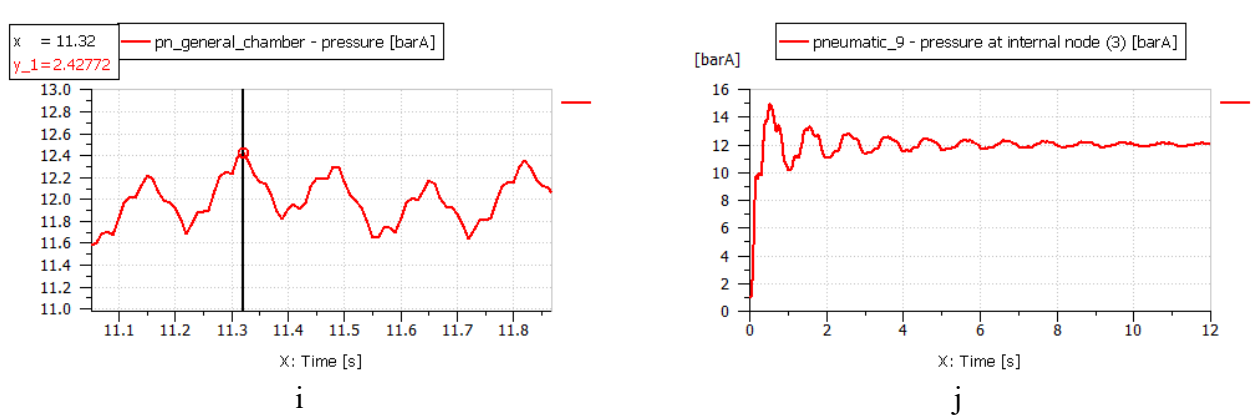

Fig. 4. Pressure variation in the active chambers of the compressor cylinders (single stage two cilinders): a. (top -down) head end cylinder 1, crank end cylinder 1 ; b. head end cylinder 2 , crank end cylinder 2; c. suction pressure; d. suction pressure detail; e. discharge pressure; f. discharge pressure detail speed $360 \mathrm{rpm}$; g. discharge pressure (detail) speed $60 \mathrm{rpm}$; h. discharge pressure (detail) speed $360 \mathrm{rpm}$ without suction valve at head end cylinder 1; i. discharge pressure (detail) speed $360 \mathrm{rpm}$, dead space doubled (24\%); j. pressure variation on discharge pipeline between segment 2 and 3 (pipeline has 6 segments).

\section{Numerical results}

Following the modeling, you can see the pressure variation diagrams in the pneumatic bottles. The suction, compression, evacuation and expansion of the gas are very well observed, see fig. 4.a for the two chambers of cylinder 1 and in the fig. 4.b for the two chambers of cylinder 2 . Regarding the pressure variation on the suction in the anti-pulsating bottle fig. 4.c and d (detail) the pressure is variable (maximum 0.08 bar peak to peak). On the discharge area due to the longer length of the pipeline $(100 \mathrm{~m})$ we have an large variation of the pressure during the stabilized movement period, fig. 4.e-f. For the numerical example from fig. $4 \mathrm{c}-\mathrm{d}$ at suction, the pressure in the anti-pulsating bottle varies from 3.96 bar to 4.04 bar. At the flange from the pipeline equation (13) the permissible pressure variation is $\frac{4.1}{4^{1 / 3}}=2,59 \%$, namely $4 \frac{2.59}{100}=0.10$ bar. At the compressor flange equation (12) the allowed pressure variation is $\min \left(3 \cdot \frac{12}{4} ; 7\right)=7 \%$, namely $4 \frac{7}{100}=$ 0.28 bar. The pressure variation (fig. 4 .d) is $4.04-3.96=0.08$ bar, below the imposed limits in the both situations. Calculating the maximum allowed pressure variation with the relations (12) and (13) for discharge we find the values: $\Delta p \%=\min (3 \cdot 3 ; 7)=7 \%$, at the cylinder flange and $\Delta p \%=\frac{4.1}{12^{1 / 3}}=1.8 \%$ at the pipeline flange.

Regarding the variation of the pressure in the anti-pulsating bottles on discharge (fig. 4.e-f) the pressure varies from 11.75 bar to 12.25 bar. At the flange from the pipeline (13) the allowed variation of the pressure is $12 \frac{1.80}{100}=0.22$ bar. The maximum pressure variation (peak to peak). is $12.25-11.75=0.5$ bar, so the maximum permissible limit is exceeded. The bottle must be resized (it must be adopted an larger volume) or we can use a filter that also has the effect of cutting vibrations over a certain threshold. At the compressor flange (12) the allowed pressure variation is $12 \frac{7}{100}=0.84$ bar. The maximum pressure variation 0.5 bar is below the imposed limit of 0.84 bar. If the crank shaft speed is lower the shape of pressure variation is different, fig. $4 . \mathrm{g}$ (for $60 \mathrm{rpm}$ ). The elimination of a suction valve fig. $4 . \mathrm{h}$ increase the pressure variation (for $360 \mathrm{rpm}, 0.80$ bar peak to peak). The increase of the dead space (24\% of displacement) generates a greater pressure variation, fig. 4.i (0.79 bar peak to peak). The influence of the compressibility of the gas in 
the dicharge pipeline can be observed. The pipeline was divided into 6 sections and in the fig. 4.j is the variation of pressure in one of the points that delimited two sections.

Discharge pipeline

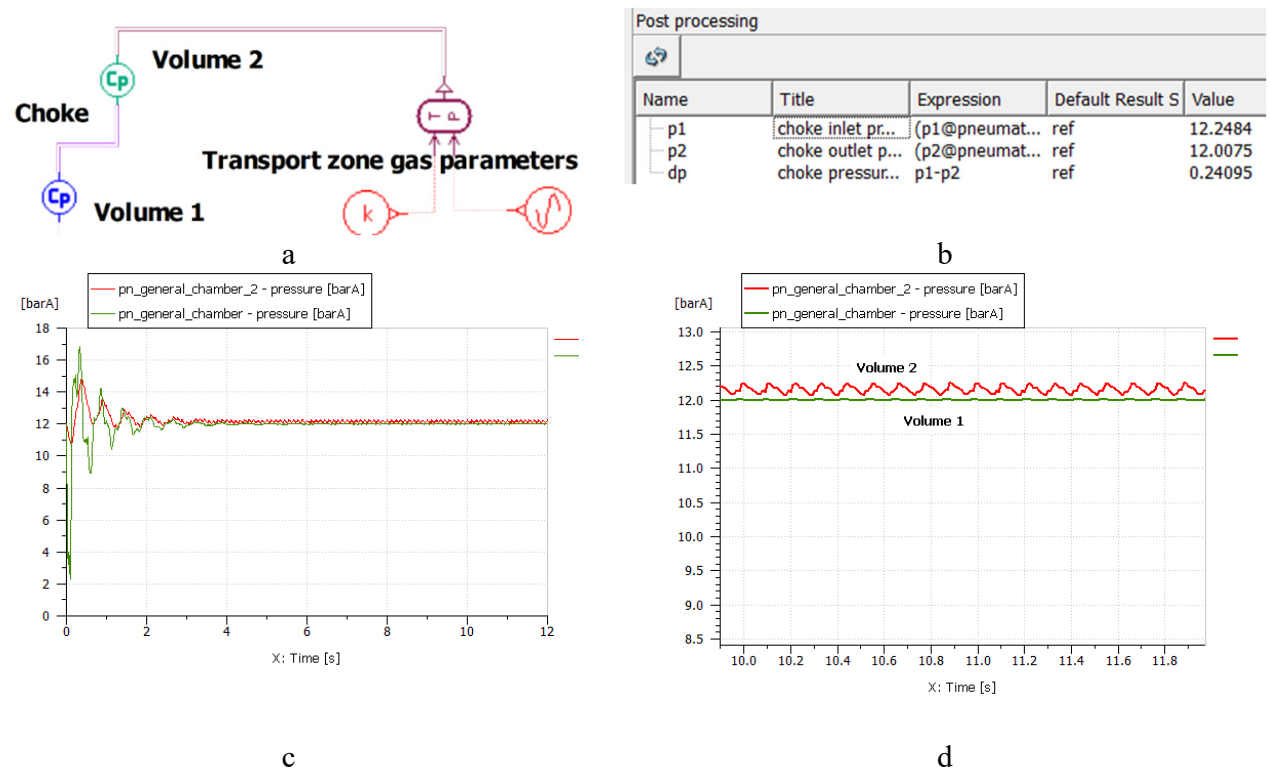

Fig. 5. Using an acoustic filter: a. model modification on the discharge pipeline end; b. pressure drop on the choke tub -establised in the post processing section; c. pressure variation in the volume 1 and volume 2 ; d. pressure variation in the volume 1 and 2 detail.

If we use an acoustic filter achived in the form volume-choke-volume (359 1, $0.55 \mathrm{~m} \mathrm{x}$ $\emptyset 30 \mathrm{~mm}, 359$ l) fig. 5.a, the variation or pressure is different at the cylinder flange and pipeline flange. We can see the absence of periodic signal at the pipeline flange and the pressure variation is near to zero (the condition (13) is met). This aspect is favorable because it prevents the pipeline and equipment distruction by vibration propagation. But the negative aspect is connected with the pressure drop. We have a pressure drop on the chocke of 0.029 bar. In fact, compressor will work at 12.029 barA (the average value) and for the value of flow of $150000 \mathrm{Scm}$ per day this means a power of $107.303 \mathrm{~kW}$ (with an acoustic filter) compared with $107.040 \mathrm{~kW}$ (in absence of the acoustic filter). In an year the additional power is $2,303 \mathrm{kWh}$.

\section{Conclusions}

Using a dynamic model gives the following advantages: simplifies the mathematical aspect using the elements from the program library; shortens the realization time of the model; it allows to obtain a model that takes into account of the: gas composition, geometric elements of compression cylinders including the dead space, compressibility of the gas on the suction / discharge pipe, variation of the pressure on the suction and discharge of the compressor, settings of the speed, dead space, valve removed / blocked in the open position; it can be easily adapted to changes in order to use an acoustic filter.

The situations of using: of an anti-pulsation bottle and an acoustic filter, with the advantages and disadvantages of each situation was exemplified with numerical results. 


\section{References}

1. Standard API 618 (2007)

2. X. Jia, B. Liu, J. Feng, X. Peng, J Vibration and Acoustics 136, 98-105 (2014)

3. Y. Zhao, J. Chen, Q. Zhou, X. Jia, X. Peng, Hindawi Shock Vibration 2017,1-12 (2017)

4. B. Howes, S. Greenfield, Proceedings of 4th Int. Pipeline Conference Calgary Canada IPC'02, $1-10(2002)$

5. E. Giacomelli, $8^{\text {th }}$ Biennial ASME Conference on Engineering Systems Design and Analysis Torino Italy, (2006).

6. K. Atkins, A. Pyle, J. Tison, Gas Machinery Conference in Albuquerque New Mexico GMRC 2004, 1-22 (2004)

7. A. Ghanbariannaeeni, G. Ghazanfarihashemi, J Process Mech. Eng. 230 (1), 65-75 (2016)

8. D. Smith, Proceedings of the Fortieth Turbomachinery Symposium Houston Texas, 170-201 (2011)

9. P. Shejal, A.D. Desai, Int. J Modern Engineering Research (IJMER) 4 (7), 1-23 (2014)

10. Z. Liu, Z. Wang, Q. Feng, X. Yu, J Process Mech. Eng. 231(3), 600-612 (2017)

11. A. Almasi, J. Process Mech. Eng. 224, 63-66 (2009)

12. A. Almasi, World Academy of Science Engineering and Technology 55, 321-329 (2009)

13. A. Okasha, T. Elnady, A. Mats, J Applied Acoustics 109, 44-53 (2016)

14. Z. Liu, J. Cheng, Q. Feng, X. Yu, J Mech. Eng. Science 231 (3), 473-484 (2017).

15. Z. Liu, Q. Feng, J Power and Energy 230 (1), 99-111 (2016)

16. F. Fifer, 73rd Annual GPA Convention New Orleans 1994, 1-6 (1994)

17. M. Elvedin, 12th International Research/Expert Conference, Trends in the Development of Machinery and Associated Technology Istanbul, Turkey TMT 2008, (2008)

18. P. Młynarczyk, P. Cyklis, J. Refrigeration 90, 108-118 (2018)

19. P. Młynarczyk, P. Cyklis, J. Sound and vibration 464, 1-17 (2020)

20. W. Bratek, U. Bhachu, J. Barss, Gas Machinery Conference San Antonio TX GMRC 2019, 1-19 (2019)

21. I. Pana, Hydrocarbon transport and storage systems (Petroleum and Gas University Publishing House, Ploiesti, 2007)

22. K. Arnold, M. Stewart, Design of Gas-Handling Systems and Facilities (2nd ed.) (Elsevier, Boston, MA, 1999)

23. R. N. Brown, Compressors - Selection and Sizing (2nd ed.) (Gulf Professional Publishing, An Imprint of Butterworth-Heinemann, Boston, MA, 1997) 